\title{
Responses of Spatiotemporal Vegetative Land Cover To Meteorological Changes in Bangladesh
}

Md. Abdul Fattah ( $\square$ mafattah.kuet@gmail.com )

Khulna University of Engineering and Technology https://orcid.org/0000-0002-8477-4446

Syed Riad Morshed

Khulna University of Engineering and Technology

\section{Research Article}

Keywords: Urban expansion, climate change, Bangladesh, NDVI

Posted Date: July 26th, 2021

DOI: https://doi.org/10.21203/rs.3.rs-674841/v1

License: (c) (i) This work is licensed under a Creative Commons Attribution 4.0 International License. Read Full License 


\section{Abstract}

Quantifying the response of vegetation cover change (VCC) to climatic variables is a gap that is mandatory for the conservation and rehabilitation of natural landscape to ensure sustainability. This study aims to assess the response of VCC to temperature and rainfall change in Bangladesh. We used (i) Landsat images to analyze VCC using image classification method, Normalized Difference Vegetation Index (NDVI) (ii) temperature and rainfall statistics to investigate the spatiotemporal variations (SV) of meteorological factors, urban lands, VCC in all the 64 districts of Bangladesh during 1990-2018 and examined their correlation. To quantify the impact of urbanization on VCC, two regression models were built between growingseason NDVI (GNDVI) and urban land proportion (PLU). Results show that the SV of precipitation, temperature, GNDVI, and PUL varied greatly among the districts. GNDVI was found closely related to climatic variables and less sensitive to climatic factor changes. There has been found a significant correlation between the trend of GNDVI and GP while the negative correlation between GNDVI trend and GT, $\triangle$ PUL. Strong sensitivity of GNDVI change to GP was calculated in the range of precipitation $2200-3000 \mathrm{~mm}$ and GNDVI to GT change in the range of temperature $30^{\circ} \mathrm{C}-31^{\circ} \mathrm{C}$. Besides, urban expansion was found mostly responsible for VCC in the study area.

\section{Introduction}

Forests and vegetation provide biodiversity protection that preserves the soil cover and balances the hydrological cycle, ecosystem, air temperatures, humidity, and rainfall which helps to mitigate climate change impacts (Zheng et al. 2019). But, due to population growth and urban expansion, human beings are destructing the forest-cover falling under the greater dominion of land surface vegetation-cover (Amera and Tefera, 2013). Due to massive Land Use/Land Cover (LULC) transformation, carbon emissions are increasing and carbon sinks are decreasing and accelerating climate change. In this sense, urbanization is one of the key factors impacting forest cover, which has profound effects on both national and global climate (Hunt et al. 2017). Land cover around the world is transforming, influenced by both natural and artificial factors (Hassan, 2017). Vegetation, one of the most important land covers of the earth's ecosystem, offers an extensive variety of social, ecological, and environmental services and benefits habitats for sustainability (Wu, 2010; Zheng et al. 2019; Robinson \& Lundholm, 2012). It helps to maintain sustainability between environment and ecology through carbon sequestration (Gratani \& Bonito, 2016) improving air quality (Escobedo \& Nowak, 2009), conserving soil and water, preserving biodiversity (Dana \& Mota, 2002), regulating microclimates (Jonsson, 2004) and mitigating disasters (Jenerette et al. 2011). However, palaeoenvironmental and palaeoecological records show that human activities and climate change have been disrupting ecosystems as well as vegetation (Marignani et al. 2016; Mercuri et al. 2015; Li \& Zhou, 2010). Over the past few decades, vegetation coverage has undergone a remarkable transformation which is greatly affecting environmental and habitat sustainability (Jin et al. 2018; Grimm et al. 2008). Understanding the relationship between climate change, dynamics of vegetation, and the services offered to humanity by ecosystems is one of the main research challenges in the 21 st century.

Environmental concern has contracted as one of the major worldwide attention that distinctly as well as jointly affect all countries (Amera and Tefera, 2013). With the expansion of population and spontaneous extension of cities, land use patterns and biological systems have changed, prompting the arrangement of metropolitan situated natural difficulties around the globe (Arsanjani et al. 2013). Land use and land cover (LULC) type has been changing quickly because of the many main impetuses. Thus, carbon emissions, environmental change, the shift of biological systems, ecological corruption, and the random condition have been expanding which making the climate of any region inadmissible for human home (Ameen and Mourshed, 2017; Zheng et al. 2017). Therefore, Bangladesh is one of the world's exceptionally populated nations, where the metropolitan population has developed after some time because of relocation from rustic to mechanical or support areas looking for work openings and driving qualified everyday environments (Zaman et al. 2010). Rapid population growth may have beneficial economic development influences but have detrimental effects on LULC change and sustainable development (Kafy et al. 2021). The urban areas of Bangladesh have been confronting the issue of spontaneous metropolitan extension like other creating urban communities (Zaman et al. 2010). The LULC management strategy is now one of the most important obstacles to the mitigation of the adverse environmental and climatic effects by limiting unplanned urban growth and promoting green coverage.

Page 2/20 
Climate is considered as the most perilous environmental factor which not only affects the ecosystem and the environment but also LULC and humans (Hunt et al. 2017). Generally, researchers use remote-sensing techniques to illustrate land use/ land cover (LUCC) changes and vegetation variations at the city level or regional level. LULC classification, net primary productivity (NPP), and normalized difference vegetation index (NDVI) are utilized for illustrating vegetation activities (Wang et al. 2008; Kafy et al. 2020). The NDVI derived from satellite data is an important indicator for evaluating the state of living green vegetation and showing vegetation dynamics reacting to climate change (Kalisa et al. 2019; Philippon et al. 2007; Zhang et al. 2013). Using the supervised image classification method, Rai et al. (2017) showed that Bangladesh has undergone a total loss of $6.2 \%$ (9054 sq km) of vegetated areas during 1976-2014. Hasan et al. (2013) have shown that total vegetation was $12.11 \%$ in $1976,9.02 \%$ in 2000 , and $9.84 \%$ in 2010 . Fu et al. (2013) have shown the NDVI changing trend exhibited spatial differences at a significant level over land surfaces around the world. Long-term climate change or interannual climatic variations can affect photosynthesis of vegetation, respiration, and organic carbon decomposition (Fu et al. 2013) and have a profound influence on vegetation cover change (VCC) (Schreider et al. 1996; Kalisa et al. 2019).

Precipitation and temperature were shown to be the main climate factors for the growth of vegetation in previous literature (Blok et al. 2011; Gessner et al. 2013). Zhou et al. (2001) showed that increase in precipitation influences to increase NDVI while temperature change causes the decrease of NDVI. Sun et al. (2011) demonstrated that rise of rainfall influences to improve vegetation cover, while in arid and semi-arid regions in China the temperature was not the limiting factor. However, several studies have demonstrated the consequences of vegetative land cover transformation on the environment in the previous literature (Kafy et al. 2021; Escobedo \& Nowak, 2009; Dana \& Mota, 2002; Jenerette et al. 2011; Marignani et al. 2016). There have been many studies on LULC change in Bangladesh (Hasan et al. 2017; Rai et al. 2017; Mukhopadhyay et al. 2018; Hasan et al. 2013) including in city-level LULC change (Ahmed, 2015; Ahmed, 2011; Ahmed et al. 2013; Kafy et al. 2020; Kafy et al. 2021). The change in temperature and rainfall pattern in Bangladesh is shown in the literature (Basak et al. 2013; Rahman \& Lateh, 2017; Hossain et al. 2019; Hossain, 2014; Kamruzzaman et al. 2019). Hossain et al. (2019) and Biswas, (2013) analyzed the impacts of rainfall on crop production. So far yet, no previous studies have assessed the responses of VCC to climatic variables in the context of Bangladesh and this important topic has been focused on insufficient studies especially the researches that have been conducted in the south Asian region.

This study detailed the interannual growing-season NDVI (GNDVI), temperature (GT), precipitation (GP), and proportion of urban land (PUL) in Bangladesh over the past three decades. And then performed a sensitivity analysis, analyzed the spatiotemporal changing trend of GNDVI, GP, GT, and PUL, examined the correlation between GNDVI and GT, GP, and PUL change to assess the response of VCC to climatic variables. Finally, the impacts of urban expansion on GNDVI dynamics are quantified through the regression model. In general, the long-term VCC should be studied in light of their history, but used recent observation records (1990-2018) to perform studies in an important 'window' of human history. The changes in vegetation, the landscape, and the climate could also represent long-term environmental changes in Bangladesh.

\section{Materials And Methods}

\subsection{Data}

We use the 30-meter cloud-free images from Google Earth Engine (GEE), based on the USGS Landsat 5 and Landsat 8 Surface Reflectance Tier 1 (Xu et al. 2020; Tassi \& Vizzari, 2020; Yu et al. 2018). The NDVI data were also obtained from GEE. Meteorological data include monthly average temperature, humidity, and annual average precipitation during the year 19912018, which were collected from the Bangladesh Meteorological Department (BMD)

(http://climate.barcapps.gov.bd/index.php). There are 34 weather stations in Bangladesh located in the main cities of the country. This study used the interpolation method in ArcGIS (Curtarelli et al. 2015; Chen et al. 2017; Ly et al. 2011) to interpolate the rainfall, temperature data and calculated the meteorological data for all the districts of the country. The annual growingseason rainfall (GP) and annual growing-season temperature (GT) were calculated based on the monthly climate data.

\subsection{Methods}

Page $3 / 20$ 


\subsubsection{Study area selection and Quantification of Urban Land Expansion}

Bangladesh is a small country of 1,47,570 sq km with complicated climatic and geographical conditions and a relatively rich ecosystem diversity. However, the rapid urban expansion has enormously impacted and altered the social, economic, and environmental conditions of Bangladesh (Hasan et al. 2017). The study area of this study encompasses entire Bangladesh (Fig. 1). It is a South Asian country located between the latitudes $20^{\circ} 340$ and $26^{\circ} 380$ north and the longitudes $88^{\circ} 010$ and $92^{\circ} 410$ east (Xu et al. 2020). The climate of the country is tropical in the south and subtropical in the center-north, the winter from November to February is pleasantly warm and sunny, a short hot spring between March and May, rainy season from June to October. Bangladesh is flat and occupied by the huge Ganges-Brahmaputra Delta, and vulnerable to floods (Yu et al. 2018).

There are 64 districts in Bangladesh under eight divisions. All the districts were eventually selected in this study. The geometric center of the urban area of each district was determined by using the Feature to Point tool in ArcGIS. For each district, a radius was determined based on the built-up area and drawn a circle which was defined urban areas as the inner zone (IZ). Exterior to this circle, a buffer area with a $10 \mathrm{~km}$ radius, the suburban areas were defined as outer zone (OZ). ArcGIS was used to count the areas of extracted urban lands during the study year in $I Z\left(A U L_{I Z}\right)$ and $O Z\left(A U L_{O Z}\right)$. Using Eq. 1, the proportion of urban lands (PUL) under IZ and OZ was calculated.

$P U L_{I Z}=\frac{A U L_{I Z}}{T A I Z} \times 100 \%$

Where, $P U L_{I Z}=$ Proportion of urban-lands in IZ (\%), $A U L_{I Z}=$ Extracted area of urban-lands in IZ (sq.km.); $T A_{I Z}=$ Total area of IZ. Similarly, $\mathrm{PUL}_{\mathrm{OZ}}$ was calculated for the year 1991 and 2018 and the change of PUL in IZ $\left(\triangle P \mathrm{PUL}_{\mathrm{IZ}}\right)$ and OZ $\left(\triangle \mathrm{PUL} \mathrm{L}_{\mathrm{OZ}}\right)$ during the year 1991 to 2018 of each district was calculated to illustrate the urban expansion rate during the study period.

\subsubsection{Analysis of Spatiotemporal Variations}

Within a district, the climate background is considered to be the same. The mean GNDVI values in IZ (GNDVI IZ) and in $0 Z$ $\left(\mathrm{GNDVI}_{\mathrm{OZ}}\right.$ ) indicate the vegetative land covers in the inner zone (urban areas) and outer zone (suburban areas) respectively. The GT and GP were determined by weather data at a nearby weather station to reflect the climate for each district in the growing season.

At first, the variations GT, GP, PUL $\mathrm{IZ}_{\mathrm{IZ}}$ and $\mathrm{PUL}_{\mathrm{OZ}}$ during the year 1991 to 2018 were analyzed for the 64 districts of Bangladesh. Then, spatiotemporal variations of $\mathrm{GNDVI}_{\mathrm{IZ}}$ and $\mathrm{GNDVI} \mathrm{OZ}_{\mathrm{Z}}$ were analyzed with respect to GT, and GP. To analyze the inter-annual variations in GT, GP and GNDVI throughout 1991-2018, linear patterns were analyzed using the ordinary lowest-quarters regression method. The GNDVI trend rates were used to illustrate the direction of change in vegetation cover (Jin et al. 2018; Zheng et al. 2019; Sarp \& Ozcelik, 2017; Jiang et al. 2014).

\subsubsection{Analyzing the Sensitivity of GNDVI to Climate Change}

Generally, the relationship between land use indices (NDVI, NDWI, NDBI) and other climatic variables are examined through correlation analysis ( $\mathrm{Li}$ et al. 2016; Bai et al. 2013; Zheng et al. 2019; Jin et al. 2018). In this study, the sensitivity assessment between GNDVI and climate factors (GT, GP) during the year 1991-2018 has been examined by Pearson's correlation analysis in ArcGIS. The relationship between GNDVI trends and climate factors (GT, GP) was also conducted using Pearson's correlation analysis method.

\subsubsection{Quantification of the Impact of Urban Expansion on GNDVI Dynamics}

As climate change in the zone IZ and $\mathrm{OZ}$ are the same within a district, the different effects of the urban expansion between IZ and $\mathrm{OZ}$ could be attributed to $\mathrm{GNDVI}_{\mathrm{IZ}}$ and $\mathrm{GNDVI}_{\mathrm{OZ}}$ trend rates (Jin et al. 2018). In this regard, the differences between the 
trends rate of $\mathrm{GNDVI}_{\mathrm{IZ}}$ and $\mathrm{GNDVI}_{\mathrm{OZ}}$ were calculated. The differences in urban land expansion rates within zone $\mathrm{IZ}$ and $\mathrm{OZ}$ were calculated by calculating the differences between $\triangle P \mathrm{PL}_{\mathrm{IZ}}$ and $\triangle \mathrm{PUL}$ OZ. Finally, the impact of urban expansion on the vegetative cover was examined by analyzing the correlations between the trend rates of $\mathrm{GNDVI}_{\mathrm{IZ}}$ and $\triangle \mathrm{PUL}_{\mathrm{IZ}}$; and between $\mathrm{GNDVI}_{\mathrm{OZ}}$ and $\triangle \mathrm{PUL} \mathrm{OZ}_{\mathrm{O}}$

\section{Results}

\subsection{Spatiotemporal Variation Analyses}

\subsubsection{Climate Factors}

The climatic condition of all the districts of Bangladesh from season to season with the longitudinal change (Fig. 3, 4). The mean annual average growing-season temperature of Bangladesh has been calculated $30.24^{\circ} \mathrm{C}$, highest temperature during the study time recorded $38.95^{\circ} \mathrm{C}$ in Rajshahi districts in 1992 and the lowest $2.6^{\circ} \mathrm{C}$ in Tetulia in 2018 . The average temperature in Bangladesh was observed from $16^{\circ} \mathrm{C}$ to $24^{\circ} \mathrm{C}$ from January to March. During April to July, the average temperature varies between $32^{\circ} \mathrm{C}$ to $34^{\circ} \mathrm{C}$ and the temperature on the west side of Bangladesh is comparatively higher than in the east (Fig. 2). The mean GP has been calculated $196.22 \mathrm{~mm}$ and $152.00 \mathrm{~mm}$ for 1994 and 2018 respectively which implied that the mean GP has been reduced with a rate of $44.218 \mathrm{~mm} /$ year or reduced by total annual precipitation $530.62 \mathrm{~mm}$. Figure $3 \mathrm{~B}$ shows that the precipitation in the west side of Bangladesh has been reduced mostly than in the east. Table 1 shows that the trend of GT and GP ranged from 0.10 to $0.30^{\circ} \mathrm{C}$ and 38.09 to $35.43 \mathrm{~mm}$ per decade respectively. The GT for 46 districts had ascending trends and 18 has descending trends and the mean change trend of GT has been recorded to be increased $0.733^{\circ} \mathrm{C}$ per decade. Most of the districts (Fig. 3A, B) experienced a decreasing trend of GP.

Table 1

Descriptive statistics of GNDVI, GP, GT and PUL for all the districts of Bangladesh.

\begin{tabular}{|c|c|c|c|c|c|c|c|c|c|c|c|}
\hline & \multirow[t]{2}{*}{ Year } & \multicolumn{4}{|c|}{ Mean value } & \multicolumn{4}{|c|}{ Change Trend } & \multirow[t]{2}{*}{$\mathrm{PUL}_{\mid Z}$} & \multirow[t]{2}{*}{$\mathrm{PUL}_{\mathrm{OZ}}$} \\
\hline & & $\mathrm{GNDVI}_{\mathrm{IZ}}$ & $\mathrm{GNDVI}_{\mathrm{OZ}}$ & GT & GP & $\mathrm{GNDVI}_{\mathrm{IZ}}$ & $\mathrm{GNDVI}_{\mathrm{OZ}}$ & GT & GP & & \\
\hline \multirow[t]{2}{*}{ Mean } & 1990 & 0.314 & 0.290 & 30.24 & 196.22 & \multirow[t]{2}{*}{0.342} & \multirow[t]{2}{*}{0.073} & \multirow[t]{2}{*}{0.733} & \multirow[t]{2}{*}{-44.218} & 5.305 & 7.109 \\
\hline & 2018 & 0.374 & 0.364 & 30.97 & 152.00 & & & & & 17.474 & 18.566 \\
\hline \multirow[t]{2}{*}{ STD } & 1990 & 0.065 & 0.102 & 0.10 & 8.12 & \multirow[t]{2}{*}{-0.002} & \multirow[t]{2}{*}{-0.006} & \multirow[t]{2}{*}{-0.032} & \multirow[t]{2}{*}{-0.473} & 7.036 & 7.450 \\
\hline & 2018 & 0.063 & 0.096 & 0.06 & 7.64 & & & & & 17.249 & 14.530 \\
\hline \multirow[t]{2}{*}{ Range } & 1990 & 0.391 & 0.657 & 0.10 & 38.09 & \multirow[t]{2}{*}{-0.036} & \multirow[t]{2}{*}{-0.009} & \multirow[t]{2}{*}{0.195} & \multirow[t]{2}{*}{-2.655} & 0.19 & 1.06 \\
\hline & 2018 & 0.355 & 0.648 & 0.30 & 35.43 & & & & & 13.94 & 29.87 \\
\hline \multirow[t]{2}{*}{ Min } & 1990 & 0.150 & -0.413 & 29.14 & 110.14 & \multirow[t]{2}{*}{-0.418} & \multirow[t]{2}{*}{-0.057} & \multirow[t]{2}{*}{0.873} & \multirow[t]{2}{*}{-29.773} & 0.012 & 0.012 \\
\hline & 2018 & -0.268 & -0.470 & 30.02 & 80.36 & & & & & 0.033 & 0.023 \\
\hline \multirow[t]{2}{*}{ Max } & 1990 & 0.657 & 0.783 & 31.83 & 368.40 & \multirow[t]{2}{*}{-1.341} & \multirow[t]{2}{*}{-0.051} & \multirow[t]{2}{*}{0.139} & \multirow[t]{2}{*}{-70.161} & 37.040 & 28.900 \\
\hline & 2018 & 0.684 & 0.731 & 31.97 & 298.24 & & & & & 70.540 & 50.560 \\
\hline
\end{tabular}

Figure 4 shows that most of the districts of Bangladesh have experienced both positive and negative climatic changes. Out of 64 districts, the average rainfall in only three districts has increased and dropped dramatically in 15 districts (Figure 4A). The negative temperature change trend in 12 districts has been calculated during the study period while the range was calculated in between $-0.146^{\circ} \mathrm{C}$ to $-0.0141^{\circ} \mathrm{C} /$ decade. The temperature change trend in 20 districts was between $0.250-0.381^{\circ} \mathrm{C} / \mathrm{decade}$ and 
between 0.381 to $0.513^{\circ} \mathrm{C} /$ decade in 9 districts (Figure 4B). The highest temperature increasing rate has been observed throughout the eastern portions of the country.

\subsubsection{Urban Lands}

Spatiotemporal urban land proportion change analysis shows the rapid urban expansion in all districts from 1990 to 2018. Figure $5 \mathrm{~A}, \mathrm{~B}$ shows that the $\mathrm{PUL}_{\mathrm{IZ}}$ and $\mathrm{PUL}_{\mathrm{OZ}}$ have increased during the study period, indicating the rapid increase of urban areas in all 64 districts of Bangladesh. The percentage of urban expansion rate varies from district to district. The $\triangle P U L_{I Z}$ was calculated less than $5 \%$ for no districts, about 26 districts $\triangle P \mathrm{PL}_{\mathrm{IZ}}$ was calculated between 5 to $19 \%$ per decade more than $48 \%$ per decade in five districts during 1900-2018 (Fig. 5A). While the value of $\triangle P \mathrm{PL}_{\mathrm{OZ}}$ was calculated more than $48 \%$ in 2 districts; between 34.29 to $48.66 \%$ in five districts; 5.56 to $19.93 \%$ in 26 districts during $1990-2018$. While one city has PUL $1 Z$ and PUL more than $60 \%$. The $\mathrm{PUL}_{\mathrm{IZ}}$ of districts in the city center and spatiotemporal land-use change shows that the urban growth has been high in the city centers and $\mathrm{PUL}_{\mathrm{OZ}}$ are mainly the suburban areas that faced less urbanization than city centers during the study period. The highest proportion of urban lands calculated $70.54 \%$ in the inner zone and $50.56 \%$ in the outer zone in 2018 and respectively $37.04 \%$ and $28.90 \%$ in 1990 . The mean $\mathrm{PUL}_{\mathrm{IZ}}$ change rate was $12.17 \%$ per decade and the mean $\mathrm{PUL}_{\mathrm{OZ}}$ change rate was $11.46 \%$ per decade during the study period (Table 1), implying that both the urban and suburban areas of Bangladesh have experienced rapid urbanization and the expansion rate was quite same.

\subsubsection{GNDVI}

Spatiotemporal distribution of mean annual GNDVI including $\mathrm{GNDVI}_{\mathrm{IZ}}$ and $\mathrm{GNDVI}_{\mathrm{OZ}}$ for all 64 districts of the country were remarkably different (Fig. 6A, B, C, D). The $\mathrm{GNDVI}_{\mathrm{IZ}}$ and $\mathrm{GNDVI}_{\mathrm{OZ}}$ ranged from 0.391 to 0.355 and 0.657 to 0.648 respectively with standard deviations of 0.065 and 0.102 (Table 1). The maximum $\mathrm{GNDVI}_{\mathrm{IZ}}$ and $\mathrm{GNDVI}_{\mathrm{OZ}}$ were calculated 0.657 and 0.783 in 1990 and 0.684 and 0.713 in 2018. Mean GNDVI $I_{I Z}$ value increased from 0.314 to 0.374 and $\mathrm{GNDVI}_{\mathrm{OZ}}$ from 0.290 to 0.364 during 1990-2018. Also, some adjacent districts with similar climate conditions had different GNDVI values.

The inter-annual variations of GNDVI during 1990-2018 also showed significant differences among the districts (Fig. 6A, B, C, D). The mean GNDVI 9 districts was less than 0.23 in 1990 and increased to 19 in 2018. About 12 districts GNDVI $\mathrm{I}_{\mathrm{IZ}}$ value was greater than 0.4 while one district has a GNDVI $I_{I Z}$ value greater than 0.5 in 1990 (Fig. 6A). In 2018, 16 districts' GNDVI value was calculated more than 0.4 (Fig. $6 \mathrm{C}$ ). The $\mathrm{GNDVI}_{\mathrm{IZ}}$ value for 20 districts experienced a decreasing trend (Fig. $\left.6 \mathrm{~A}, \mathrm{C}\right)$ and the GNDVI $\mathrm{OZ}_{\mathrm{Z}}$ value for 10 districts experienced decreasing trend (Fig. 6B, D). The average trend rate of GNDVI $\mathrm{I}_{\mathrm{Z}}$ and GNDVI $\mathrm{IZZ}$ were 0.021 and 0.026 per decade respectively while the trend rate of $G N D V I_{I Z}$ was greater than 0.05 per decade in the 10 districts and $\mathrm{GNDVI}_{\mathrm{OZ}}$ greater than 0.05 per decade in the 8 districts in Bangladesh. Districts with increasing GNDVI trends mostly located in the eastern part of the country especially the capital city has experienced the most GNDVI change.

\subsection{Sensitivity of GNDVI and Climate}

\subsubsection{Relationship between Mean Annual GNDVI and Climate}

The lower $\mathrm{GNDVI}_{\mathrm{IZ}}$ was calculated when the GT was more than $31.5^{\circ} \mathrm{C}$ and the GP less than $150 \mathrm{~mm}$ (Fig. 7) and good vegetation density has been observed within the GT range between 30 to $31.5^{\circ} \mathrm{C}$ and the GP range between 125 to $300 \mathrm{~mm}$. The highest $\mathrm{GNDVI}_{\mathrm{IZ}}$ value (0.565) occurred when $\mathrm{GT}$ was $30.74^{\circ} \mathrm{C}$ and $\mathrm{GP}$ was $247.20 \mathrm{~mm}$ and the lowest GNDVI $\mathrm{I}_{\mathrm{IZ}}$ value (0.200) occurred when GT was $31.57^{\circ} \mathrm{C}$ and $\mathrm{GP}$ was $107.96 \mathrm{~mm}$. The $\mathrm{GNDVI}$ OZ value occurred low (0.274) while GT was recorded $30.23^{\circ} \mathrm{C}$ and GP $121.29 \mathrm{~mm}$ and high (0.576) while GT was $30.74^{\circ} \mathrm{C}$ and $\mathrm{GP} 254.36 \mathrm{~mm}$ (Fig. 7B).

The linear regression analysis in Fig. 9 shows that the GNDVI was positively correlated with the climatic factors (GT and GP). The correlation coefficients between average GP, GT, and GNDVI were significant at the significant level of 0.01 . The Pearson's correlation coefficient values $(0.1904,-0.1211,0.238,0.14393)$ and correlation coefficient values $(0.03626,0.1027,0.05664$, $0.02072)$ in Fig. 9 indicates that the mean annual GNDVI are closely related to the climate variables. 


\subsubsection{Relationship between GNDVI Variations and Climate Change}

The correlation between the GNDVI trend rate with GT, GP, $\triangle P U L$ trend rates has been examined through identifying Pearson correlation value and Ordinary least squares regression coefficient value (Fig. 9, 10, 11, and Table 2). The analysis shows that the correlation between the GP and GNDVI was significant for most of the districts. Table 2 shows that the correlation between GNDVI trends (Both for IZ and OZ) with GP was negatively correlated so was the proportion of urban land change during 1990-2018. However, Fig. 9 shows that the correlation between GT and $\Delta$ PUL was insignificant for most of the districts of Bangladesh. The Pearson correlation coefficient test results in Table 2 indicate the correlations between the trend rates of GNDVI and GT, GNDVI and $\triangle \mathrm{PUL}, \mathrm{GNDVI}$ and GP are insignificant. The $\triangle \mathrm{PUL}$ trends in the districts of Bangladesh located in the western part of the country were found more sensitive GT than the districts located in the eastern part. While the GNDVI trends of the districts located in the Dhaka, Khulna, Sylhet divisions were found less sensitive to climatic factors rather than the Chittagong, Rajshahi, Rangpur divisions. The overall sensitivity analysis of inter-annual variations of GNDVI was found less sensitive to the changes of GP and GT.

Table 2

The result of the correlation test for all 64 districts.

\begin{tabular}{|c|c|c|c|c|c|}
\hline & Method & GT trend & GP trend & $\Delta P L_{I Z}$ & $\Delta \mathrm{PUL}_{\mathrm{OZ}}$ \\
\hline \multirow[t]{2}{*}{$\mathrm{GNDVI}_{\mathrm{IZ}}$ trend rate } & PC & -0.114 & $0.216^{*}$ & -0.155 & -0.028 \\
\hline & OLSRC & -0.37 & 0.087 & 0.222 & 0.824 \\
\hline \multirow[t]{2}{*}{$\mathrm{GNDVI}_{\mathrm{OZ}}$ trend rate } & PC & -0.089 & $0.218^{*}$ & -0.156 & -0.079 \\
\hline & OLSRC & -0.483 & 0.084 & -0.217 & -0.533 \\
\hline
\end{tabular}

$\mathrm{PC}=$ Pearson correlation value, $\mathrm{OLSRC}=$ Ordinary least squares regression coefficient value. * indicates that correlation is significant at the 0.05 level.

\subsection{Impact of Urbanization on GNDVI Change}

The correlation value in Table 2 indicates the positive correlations between GNDVI and $\triangle \mathrm{PUL}$ indicates that the urban expansion is closely associated with the vegetation cover change in all the districts. The negative trend rate of GNDVI $I_{I Z}$ was found for 20 districts and $\mathrm{GNDVI}_{\mathrm{OZ}}$ for 10 districts, which indicates that the trend of GNDVI rate in the urban areas of Bangladesh is lower than the suburban or rural areas. The lowest GNDVI trend rate was calculated - 0.046 (per decade) for Gaibandha, $\mathrm{GNDVI}_{\mathrm{OZ}}-0.032$ (per decade) for Rangpur district, while the highest $\mathrm{GNDVI}_{\mathrm{IZ}}$ trend rate 0.080 per decade and $\mathrm{GNDVI}_{\mathrm{OZ}}$ trend rate 0.070 for Maulvibazar district.

Figure 13 shows that the GNDVI $I_{\mathrm{IZ}-0 \mathrm{Z}}$ trend rate (per decade) is negatively correlated with the trend rate of $\Delta \mathrm{PUL} \mathrm{L}_{\mathrm{IZ}-\mathrm{OZ}}\left(\mathrm{R}^{2}=\right.$ 0.01236 , Pearson's $r=-0.1119$ ). The trends in urbanized GNDVI were calculated by replacing $\triangle P U L_{I Z}$ and $\Delta \mathrm{PUL}_{0 Z}$ respectively from all the districts in this regression equation (the constant being zero). We find that urbanization in urban and suburban regions in most districts has had a negative effect on GNDVI increase. The impact of the urban expansion trend on GNDVI change was calculated to be -0.0213 per decade in the inner zone (IZ) and -0.0262 per decade in the outer zone (OZ) during 1900-2018 which implies that suburban areas of Bangladesh have experienced a greater amount of vegetation loss and urban expansion trend during the study period.

\section{Discussion}

\subsection{Diversities in the Spatiotemporal Distribution of Mean GNDVI}

Urbanization or urban area expansion is currently an increasingly active driving force of LULC transformation around the world and can be characterized by long-term impacts on environmental and ecological degradation and unsustainability (Jin et al. 2018; Wu, 2010; Mercuri et al. 2015). This study illustrated the variations of GNDVI and GNDVI changes in all the districts of 
Bangladesh. The analysis shows that the GNDVI among all the districts was remarkably different. This due to not only the different climatic changes but also to the different urbanization levels or development trends or urban expansions rate in the districts. Previous literature shows the variations in urban expansion trend in the major cities of Bangladesh so as NDVI (Ahmed, 2011; Ahmed, 2015; Ahmed et al. 2013; Kafy et al. 2020; Kafy et al. 2021; Rai et al. 2017). The increase of built-up is influenced by the declination of vegetative areas (Kafy et al. 2021). In large cities such as Dhaka, Chattogram, Khulna, Comilla, and Rajshahi, urban areas include a large percentage of buildings or high density of built-up areas (Rai et al. 2017) resulting in the lower value of NDVI. According to Mukhopadhyay et al. (2018), the urbanization trend in the suburban areas was moderately high than the urban areas as the cities are expanding. This is confirmed by the GNDVI change in Fig. 6 and the change rate in Fig. 12, where the GNDVI values and GNDVI change trend in OZ were estimated higher than in IZ. Despite this, a positive linear correlation has been found between GNDVI changes and climatic factors (Fig. 8). Therefore, the spatial disparity between the districts with the average GNDVI is related to climate factors, but urban development could play some role at the local level.

\subsection{Driving Forces of the Temporal Inconsistency of GNDVI}

This study found the GNDVI change in all the districts of Bangladesh was less sensitive to change in climatic factors. A moderate number of districts located in the western part of the country (Fig. 9) showed a significant correlation between GT and GNDVI while a significant positive correlation has been estimated between GP and GNDVI (Table 2). GP was found more sensitive to GNDVI when monthly total rainfall was more than $220 \mathrm{~mm}$ i.e., strong sensitivity of vegetation to precipitation in the districts where annual total rainfall ranged from 2200 to $3000 \mathrm{~mm}$. The strong sensitivity of vegetation to temperature was found in the districts where the average temperature ranged from 30 to $31^{\circ} \mathrm{C}$.

Urbanization is considered more responsible than climatic factors for the declination of vegetation cover areas in the urban areas and thus mask the effects of climate (Li et al. 2016; Sun et al. 2011). For instance, urban expansion in the cities driven by urbanization could directly transform a large portion of agricultural lands or waterbodies into built-up areas (Hassan \& Southworth, 2018; Hasan et al. 2017; Jarah et al. 2019). This can disrupt the connection between vegetation and precipitation by the effects of urban land expansion (Buyantuyev \& Wu, 2009). The discrepancy of the interannual GNDVI variation between $\mathrm{IZ}$ and $\mathrm{OZ}$ in Fig. 12 ensured the impacts of urban expansion in Bangladesh. The GNDVI change trend in many adjacent districts showed great differences while the climatic factors in the adjacent cities are quite similar. Moreover, the GNDVI trend rate in urban and suburban areas was found different within a district and in suburban areas, urban land is expanding at a higher rate than in urban areas. This difference was considered as a consequence of urban land expansion instead of climate fluctuations particularly because, during the study period, Bangladesh underwent rapid urbanization.

\section{Conclusions}

Vegetative land cover enriches both urban and rural life with numerous social and environmental services as well as economic services. But historical records show that over the past decades, these vegetative areas have been transformed enormously with the influence of human activities and climate change. This study investigated the variations of spatiotemporal vegetation cover in Bangladesh and its sensitivity to climatic factor change through assessing the variations of interannual growingseason NDVI, precipitation, and temperature change in all the districts of Bangladesh. The quantitative assessment of the effect of urban expansion on VCC in urban and suburban areas was also done. The study found great differences of mean annual GNDVI, GP, GT, and PUL districts to districts in Bangladesh so as the changes of GP, GT, GNDVI, and PUL. The PUL change rate was found a minimum of $0.53 \%$ per decade to a maximum of $21.30 \%$ per decade while $\mathrm{PUL}_{\mathrm{OZ}}$ was a minimum of $0.39 \%$ per decade to a maximum of $9.41 \%$ per decade indicating that Bangladesh underwent rapid urbanization during 19902018. The GNDVI $I_{I Z}$ ranged from $0.391-0.355$ and $\mathrm{GNDVI}_{\mathrm{OZ}} 0.657-0.648$ per decade. For most of the districts, the suburban area or $\mathrm{OZ}$ has experienced more severe vegetative cover loss than urban areas or IZ, the opposite also occurred. The overall study demonstrated that the vegetative cover loss was less sensitive to climatic factors and negatively correlated with the urban expansion in Bangladesh. Thus, this study addressed the long-term impact of human activities on the eco-friendly land 
cover and natural biotas and signifies the importance of adopting plans for managing and conserving the ecological environment for the future.

\section{Declarations}

Authors' contribution: Conceptualization, writing-original draft preparation, resources, graphs and charts [Md. Abdul Fattah], Formal analysis and investigation, writing-review and editing, Methodology [Syed Riad Morshed].

Code Availability: Will be available on reasonable request.

Availability of data and material: The datasets generated during and/or analyzed during the current study are available from the corresponding author on reasonable request.

Ethics Approval: This article does not contain any studies with human participants or animals performed by any of the authors.

Consent to Participate: Not applicable.

Consent to publish: Not applicable.

Declaration: The authors declare that they have no known competing financial interests or personal relationships that could have appeared to influence the work reported in this paper.

Funding: This research did not receive any specific grant from funding agencies in the public, commercial, or not-for-profit sectors.

\section{References}

1. Ahmed B (2011) Modeling Spatio-Temporal Urban Land Cover Growth Dynamics Using Remote Sensing and GIS Techniques: A Case Study of Khulna City. Journal of Bangladesh Institute of Planners 4:15-32

2. Ahmed et al (2013) Simulating Land Cover Changes and Their Impacts on Land Surface Temperature in Dhaka, Bangladesh. Remote Sensing 5(11):5969-5998

3. Ameen RF, Mourshed M (2017) Urban environmental challenges in developing countries. A stakeholder perspective. Habitat International 64:1-10

4. Amera AM, Tefera B (2013) The role of Environmental Impact Assessment for sustainable development. IAIA13 Conference At: Calgary Stampede BMO Centre, 33. Calgary, Alberta, Canada

5. Bai J et al (2013) Spatio-temporal change of vegetation NDVI and its relations with regional climate in Northern Shaanxi Province since implementation of returning farmland to forests project. In Proceedings of the 2013 Second International Conference on Agro-Geoinformatics (Agro-Geoinformatics). Fairfax, VA, USA: IEEE Xplore

6. Basak JB et al (2013) Climate Change in Bangladesh: A Historical Analysis of Temperature and Rainfall Data. Journal of Environment 2(2):41-46

7. Biswas M (2013) Climate Change \& its Impacts on Bangladesh. Bangladesh Institute of Planners, Dhaka

8. Blok D, B et al (2011) The response of Arctic vegetation to the summer climate: relation between shrub cover, NDVI, surface albedo and temperature. Environmental Research Letters, 6(3)

9. Buyantuyev A, Wu J (2009) Urbanization alters spatiotemporal patterns of ecosystem primary production: A case study of the Phoenix metropolitan region, USA. J Arid Environ 73(4-5):512-520

10. Chen et al (2017) Comparison of Spatial Interpolation Schemes for Rainfall Data and Application in Hydrological Modeling. Water 9(5):342

11. Curtarelli M et al (2015) Assessment of Spatial Interpolation Methods to Map the Bathymetry of an Amazonian Hydroelectric Reservoir to Aid in Decision Making for Water Management. ISPRS International Journal of Geo-Information 
4:220-235

12. Dana E, Mota J (2002) Urban vegetation of Almería City-a contribution to urban ecology in Spain. Landscape Urban Planning 59(4):203-216

13. Escobedo F, Nowak D (2009) Spatial heterogeneity and air pollution removal by an urban forest. Landscape Urban Planning 90(3-4):102-110

14. Fu Y et al (2013) Assessment Impacts of Weather and Land Use/Land Cover (LULC) Change on Urban Vegetation Net Primary Productivity (NPP): A Case Study in Guangzhou, China. Remote sensing, 5(8), 4125-4144

15. Gessner U et al (2013) The relationship between precipitation anomalies and satellite-derived vegetation activity in Central Asia. Global Planet Change 110(A):74-87

16. Gratani L, Bonito A (2016) Carbon sequestration of four urban parks in Rome, 19. Urban Forestry \& Urban Greening, pp 184-193

17. Grimm N et al (2008) Global Change and the Ecology of Cities. Science 319(5864):756-760

18. Hasan MN et al (2013) Agricultural Land Availability in Bangladesh. Soil Resource Development Institute, Ministry of Agriculture, Bangladesh, Dhaka

19. Hasan S et al (2017) Projections of Future Land Use in Bangladesh under the Background of Baseline, Ecological Protection and Economic Development. Sustainability 9(4):505

20. Hassan MM (2017) Monitoring land use/land cover change, urban growth dynamics and landscape pattern analysis in five fastest urbanized cities in Bangladesh. Remote Sens Appl: Soc Environ 7:69-83

21. Hassan MM, Southworth J (2018) Analyzing Land Cover Change and Urban Growth Trajectories of the Mega-Urban Region of Dhaka Using Remotely Sensed Data and an Ensemble Classifier. Sustainability, 10(1)

22. Hossain MF (2014) Impact of climate change in Bangladesh: rainfall. International Journal of Agriculture Innovations Research 2:860-863

23. Hossain MS et al (2019) Climate change and crop farming in Bangladesh: an analysis of economic impacts. Climate change crop farming in Bangladesh: an analysis of economic impacts 11(3):424-440

24. Hunt JC et al (2017) Climate change and growing megacities: hazards and vulnerability. Proceedings of the Institution of Civil Engineers-Engineering Sustainability, pp. 314-326

25. Jarah S et al (2019) Urbanization and Urban Sprawl Issues in City Structure: A Case of the Sulaymaniah Iraqi Kurdistan Region. Sustainability 11(2):485

26. Jenerette $\mathrm{G}$ et al (2011) Ecosystem services and urban heat riskscape moderation: water, green spaces, and social inequality in Phoenix, USA. Ecological Applications, 21(7)

27. Jiang $\mathrm{H}$ et al (2014) An Automated Method for Extracting Rivers and Lakes from Landsat Imagery. Remote Sensing 6:5067-5089

28. Jin K et al (2018) Responses of Vegetation Cover to Environmental Change in Large Cities of China. sustainability, 10(1), 270

29. Jonsson P (2004) Vegetation as an urban climate control in the subtropical city of Gaborone, Botswana. International Journal of Climatology, 24(10)

30. Kafy A-A et al (2020) Modelling future land use land cover changes and their impacts on land surface temperatures in Rajshahi, Bangladesh. Remote Sensing Applications: Society and Environment, 18(2)

31. Kalisa W et al (2019) Assessment of climate impact on vegetation dynamics over East Africa from 1982 to 2015. Sci Rep 9:16865

32. Kamruzzaman M et al (2019) Future Changes in Precipitation and Drought Characteristics over Bangladesh under CMIP5 Climatological Projections. Water 11(11):2219

33. Li H et al (2016) Human Impact on Vegetation Dynamics around Lhasa, Southern Tibetan Plateau. China Sustainability $8(11): 1146$

Page $10 / 20$ 
34. Li Y, Zhou L (2010) Palaeoecological records of environmental change and cultural development from the Liangzhu and Qujialing archaeological sites in the middle and lower reaches of the Yangtze River. Quatern Int 227(1):29-37

35. Ly S et al (2011) Geostatistical interpolation of daily rainfall at catchment scale: the use of several variogram models in the Ourthe and Ambleve catchments, Belgium. Hydrological Earth System Sciences 15(7):2259-2274

36. Mercuri A et al (2015) Palaeoecology and long-term human impact in plant biology. Journal of the Societa Botanica Italiana 149(1):136-143

37. Mukhopadhyay A et al (2018) Land Cover and Land Use Analysis in Coastal Bangladesh. In: Nicholls R, Hutton C, Adger W, Hanson S, Rahman M, Salehin M (eds) Ecosystem Services for Well-Being in Deltas. Palgrave Macmillan, Cham, pp 367381

38. Philippon $\mathrm{N}$ et al (2007) Characterization of the Interannual and Intraseasonal Variability of West African Vegetation between 1982 and 2002 by Means of NOAA AVHRR NDVI Data. J Clim 20(7):1202-1218

39. Rahman MR, Lateh H (2017) Climate Change in Bangladesh: A Spatio-Temporal Analysis and Simulation of Recent Temperature and Rainfall Data Using GIS and Time Series Analysis Model. Theoret Appl Climatol, 128(1-2), 27-41

40. Rai R et al (2017) A Synthesis of Studies on Land Use and Land Cover Dynamics during 1930-2015 in Bangladesh. Sustainability 9(10):1866

41. Robinson S, Lundholm J (2012) Ecosystem services provided by urban spontaneous vegetation. Urban Ecosystems 15:545-557

42. Sarp G, Ozcelik M (2017) Water body extraction and change detection using time series: A case study of Lake Burdur, Turkey. Journal of Taibah University for Science 11(3):381-391

43. Schreider $S$ et al (1996) Estimation of possible climate change impacts on water availability, extreme flow events and soil moisture in the Goulburn and Ovens Basins, Victoria. Clim Change 34:513-546

44. Sun J et al (2011) NDVI indicated characteristics of vegetation cover change in China's metropolises over the last three decades. Environ Monit Assess 179:1-14

45. Tassi A, Vizzari M (2020) Object-Oriented LULC Classification in Google Earth Engine Combining SNIC, GLCM, and Machine Learning Algorithms. Remote Sensing 12(22):3776

46. Wang $\mathrm{J}$ et al (2008) Assessing vegetation dynamics impacted by climate change in the southwestern karst region of China with AVHRR NDVI and AVHRR NPP time-series. Environ Geol 54:1185-1195

47. Wu J (2010) Urban sustainability: an inevitable goal of landscape research. Landscape Ecol 25:1-4

48. Xu X et al (2020) Dynamics and drivers of land use and land cover changes in Bangladesh. Reg Environ Change 20:54

49. Yu Z et al (2018) Land Use and Land Cover Classification for Bangladesh 2005 on Google Earth Engine. 7th International Conference on Agro-geoinformatics (Agro-geoinformatics) (pp. 1-5). Hangzhou, China: IEEE Xplore

50. Zaman AH et al (2010) Urbanization in Bangladesh: Present Status and Policy Implication. ASA University Review 2(2):116

51. Zhang J-H et al (2013) A Global Respondence Analysis of LAl Versus Surface Air Temperature and Precipitation Variations. Chinese Journal of Geophysics 45(5):662-669

52. Zheng K et al (2019) Impacts of climate change and human activities on grassland vegetation variation in the Chinese Loess Plateau. Science of The Total Environment 660:236-244

53. Zhou L et al (2001) Variation in northern vegetation activity inferred from satellite data of vegetation index during 1981 to 1999. Journal of Geophysical Research Atmospheres 106(D17):20069-20084

\section{Figures}




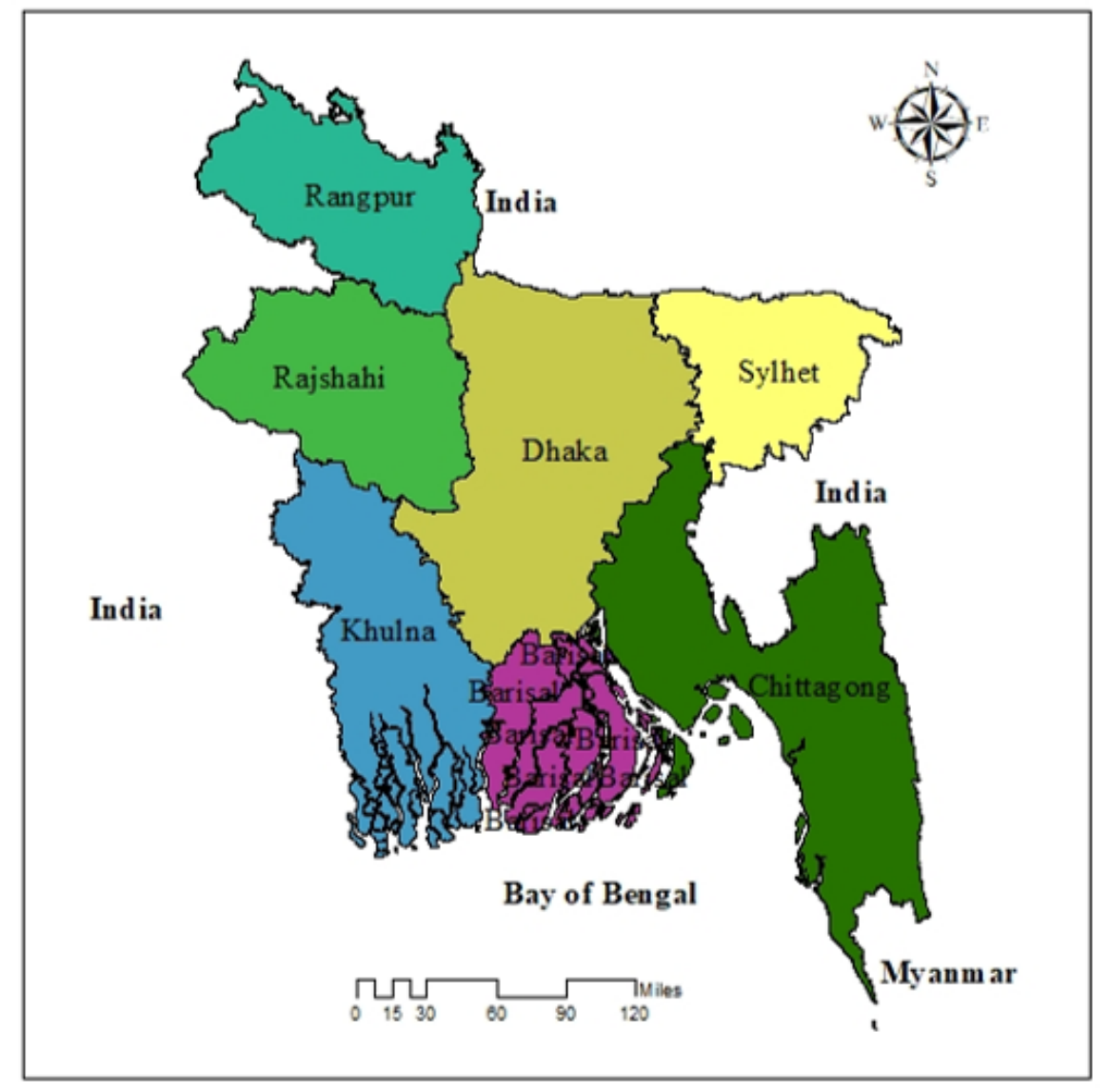

Figure 1

Study area map.
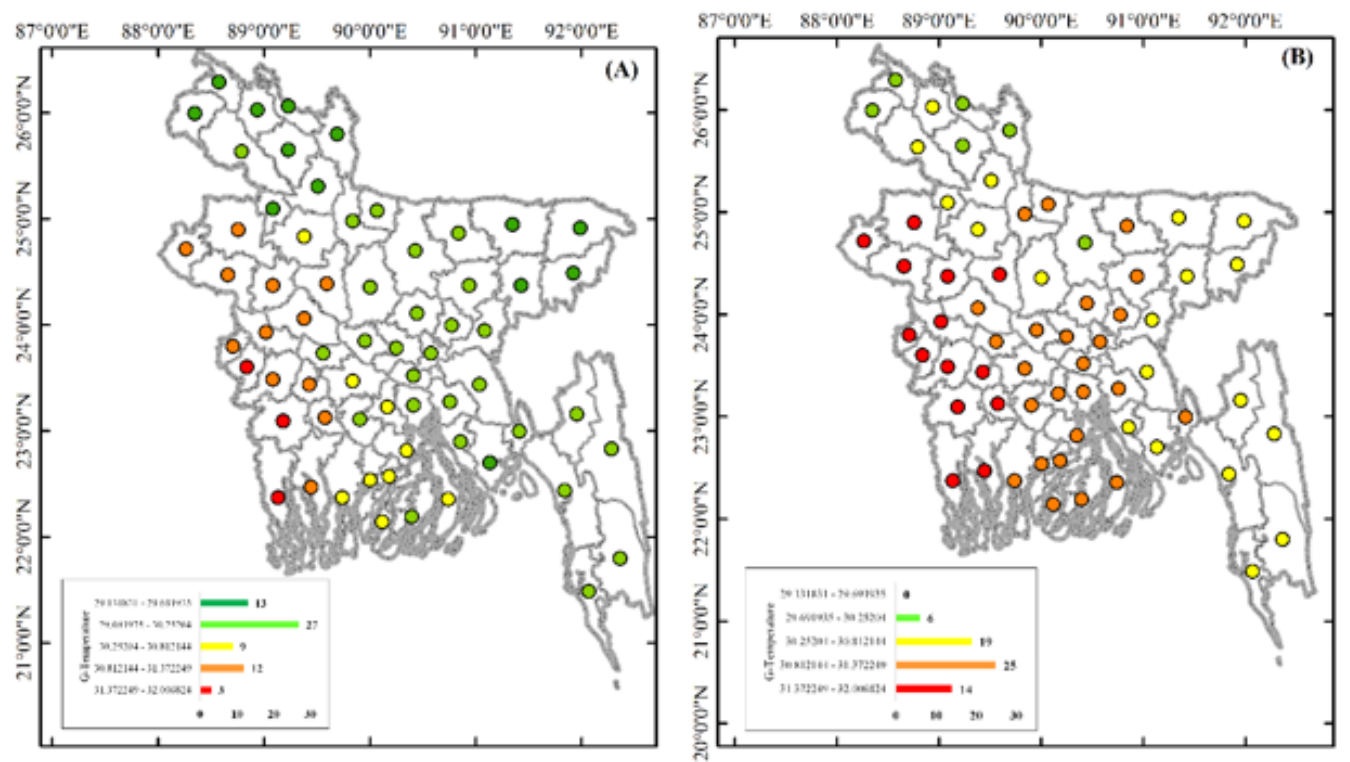

G-Temperature $\left({ }^{\circ} \mathrm{C}\right.$ )

- $29.131831-29.691935 \circ 30.812144-31.372249$

○ $29.691935-30.25204 \odot 31.372249-32.006824$

- $30.25204-30.812144$
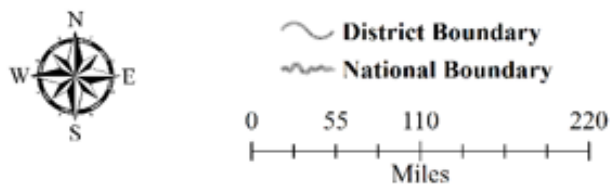

Figure 2 
Spatiotemporal distribution of (A) GT and (B) interannual variations of GT during 1990-2018.
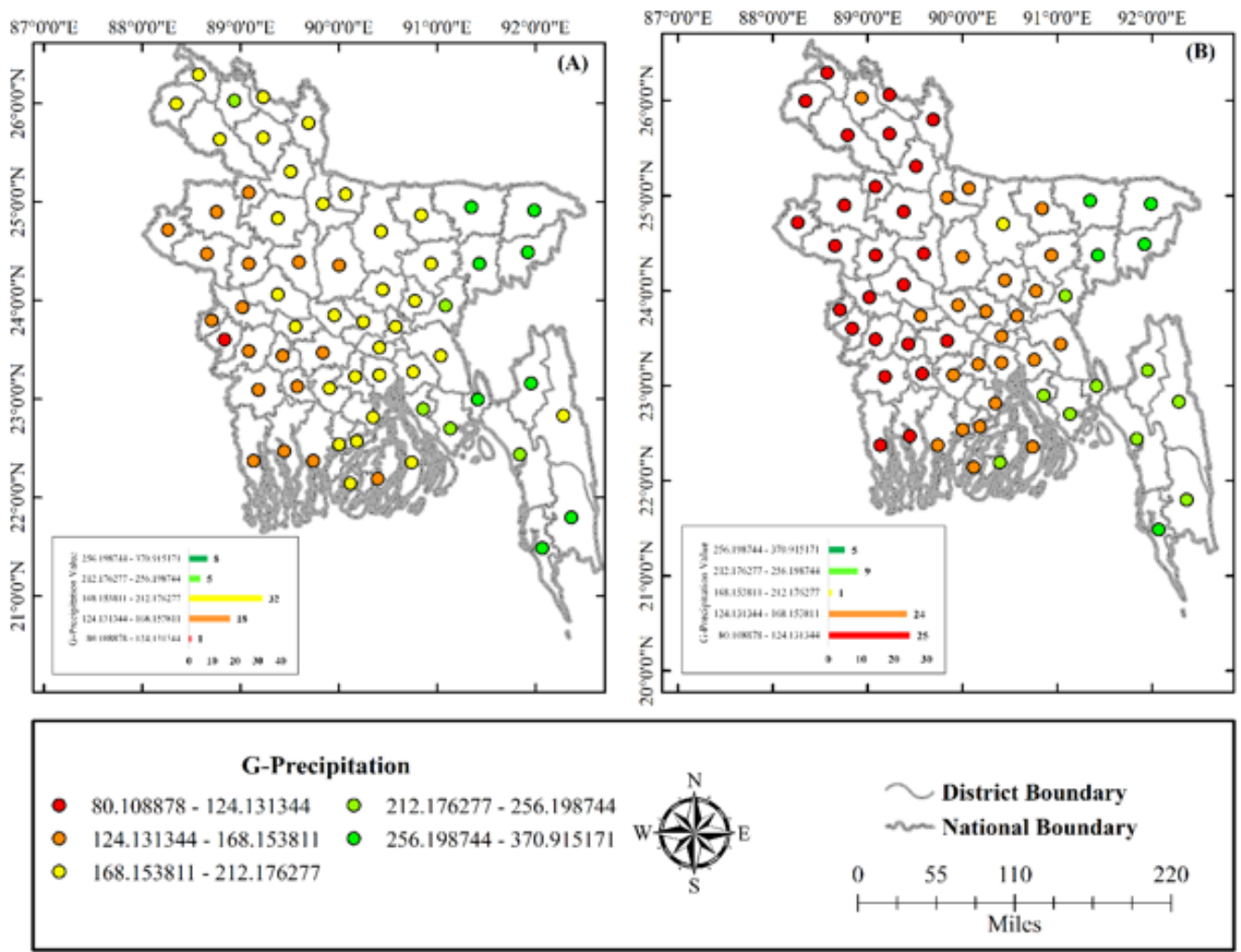

\section{Figure 3}

Spatiotemporal distribution of (A) GP and (B) interannual variations of GP during 1990-2018.
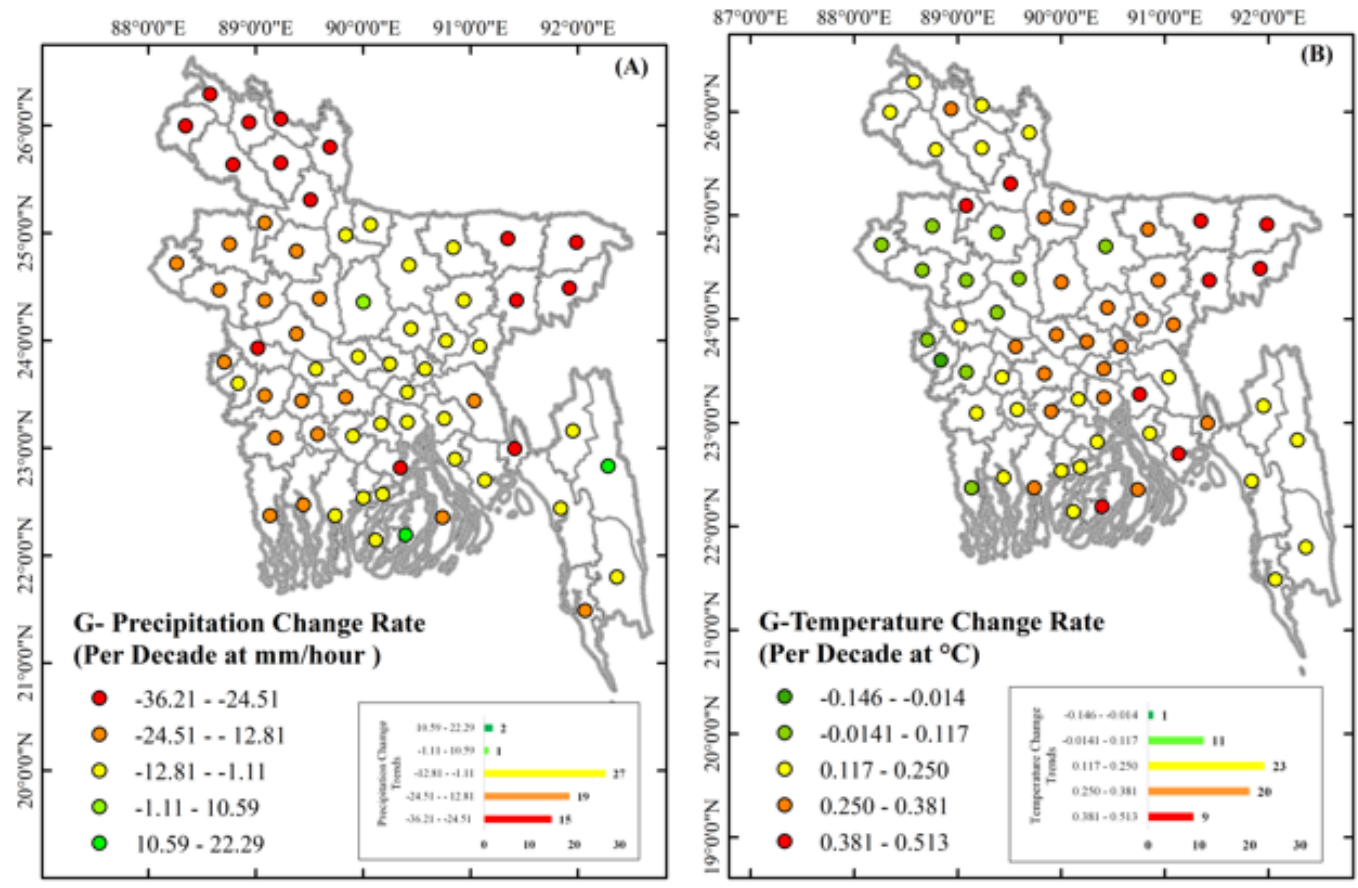

\section{$\frown$ District Boundary}

$\sim$ National Boundary

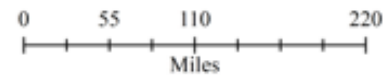

Figure 4 
Calculated climatic factors change trend rate during the study area (A) precipitation (B) temperature.
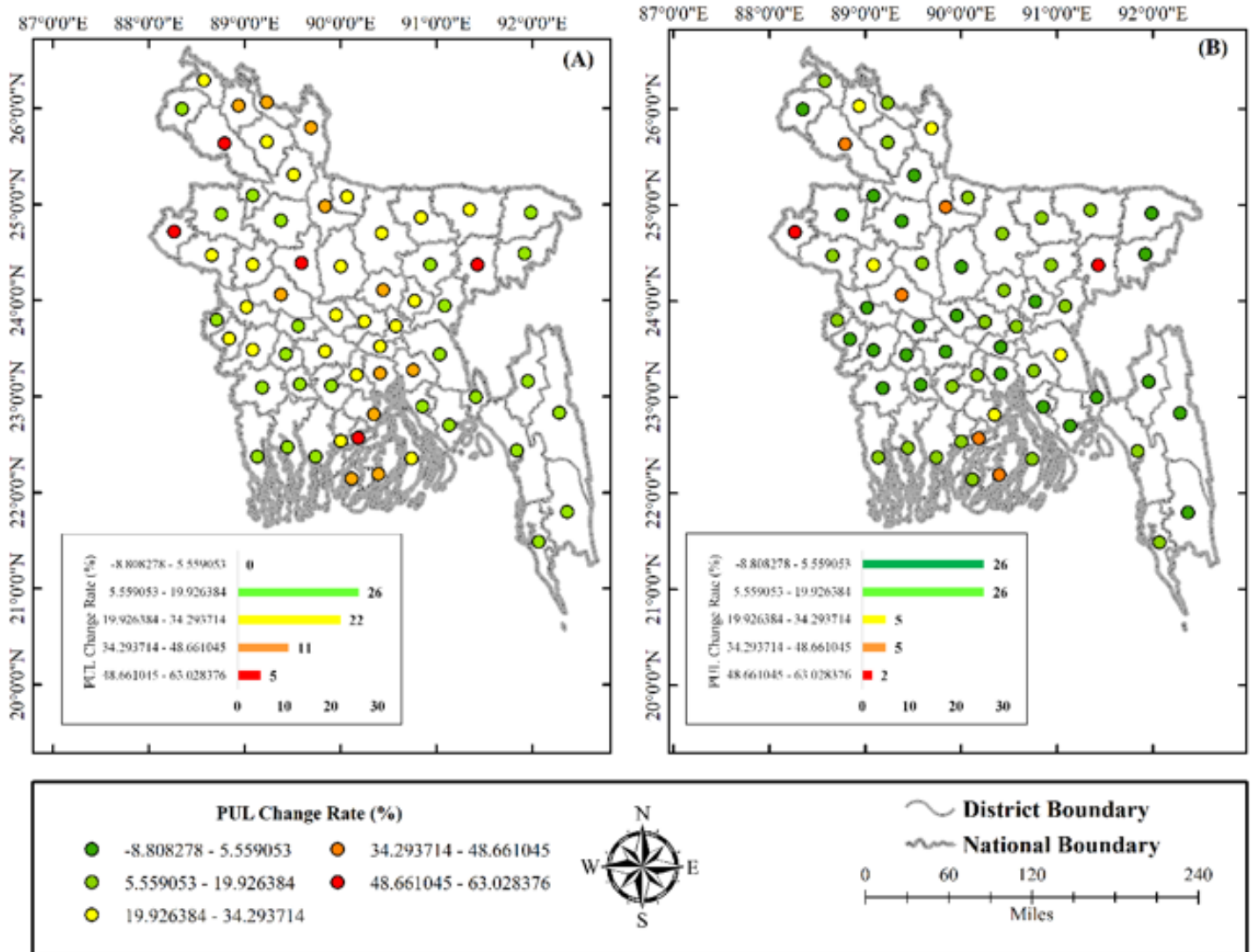

\section{Figure 5}

Spatiotemporal distribution of (A) $\triangle \mathrm{PULIZ}$ and (B) $\triangle \mathrm{PULOZ}$ during 1990-2018. 


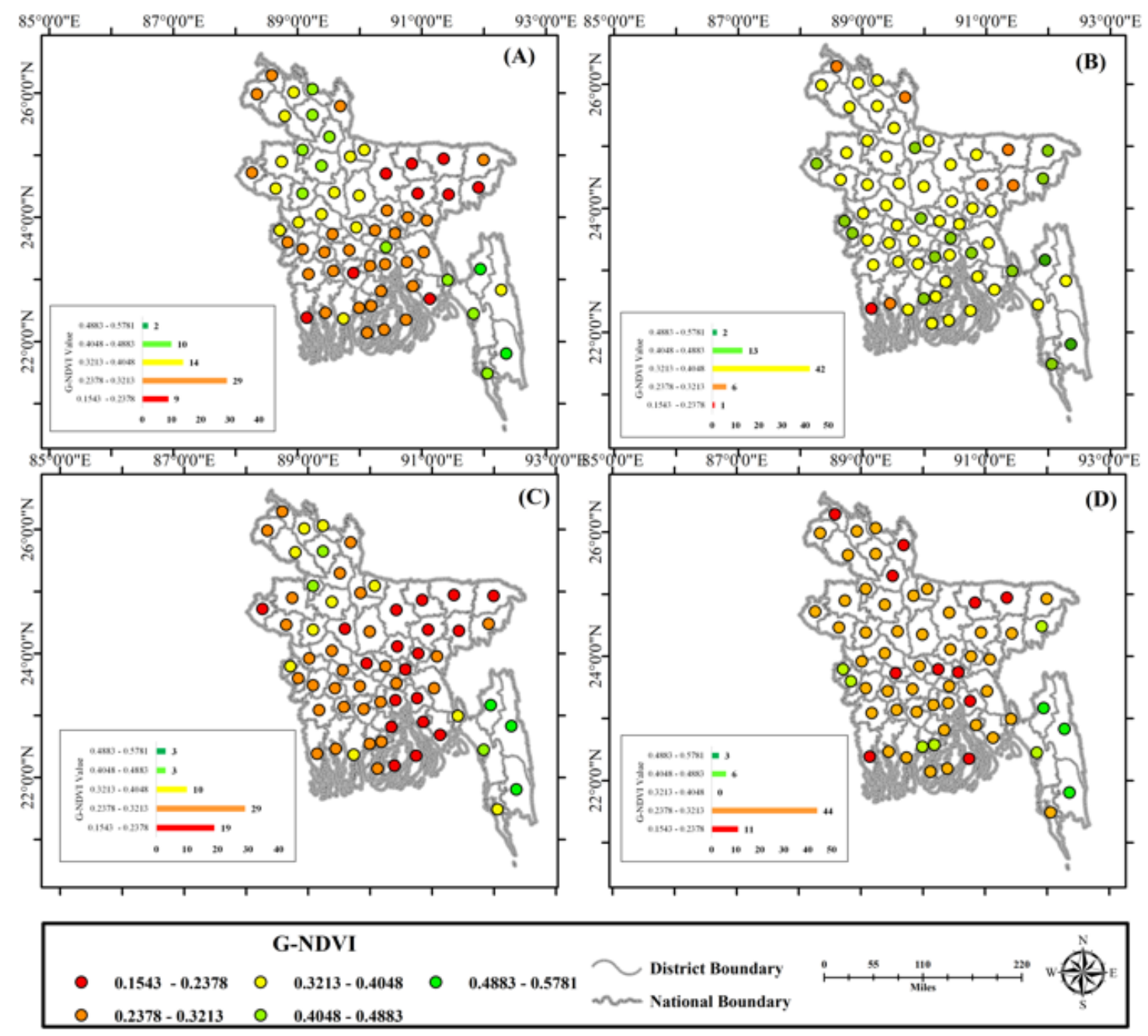

Figure 6

Spatiotemporal distribution of mean annual (A) GNDVIIZ and (B) GNDVIOZ in 1990, (C) GNDVIIZ and (D) GNDVIOZ in 2018.

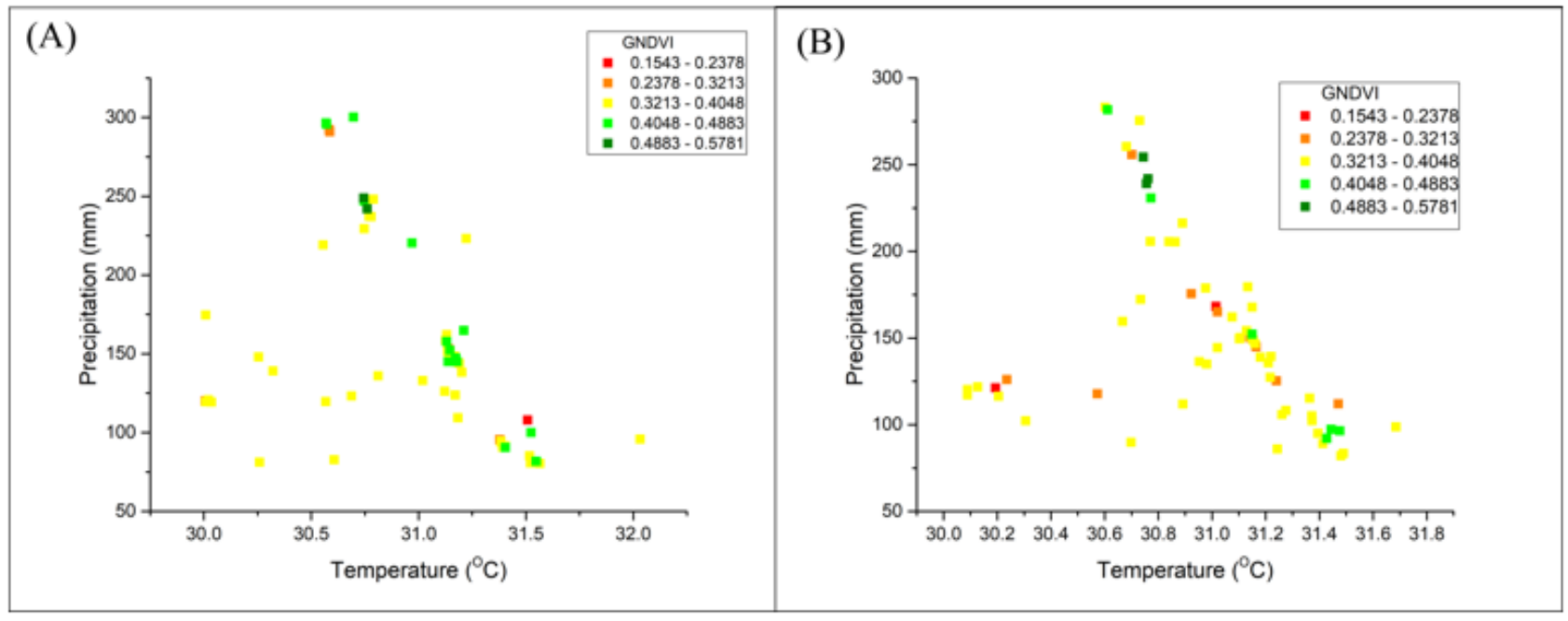

Figure 7

Relationship of GP, GT, and (A) GNDVIIZ (B) GNDVIOZ. 


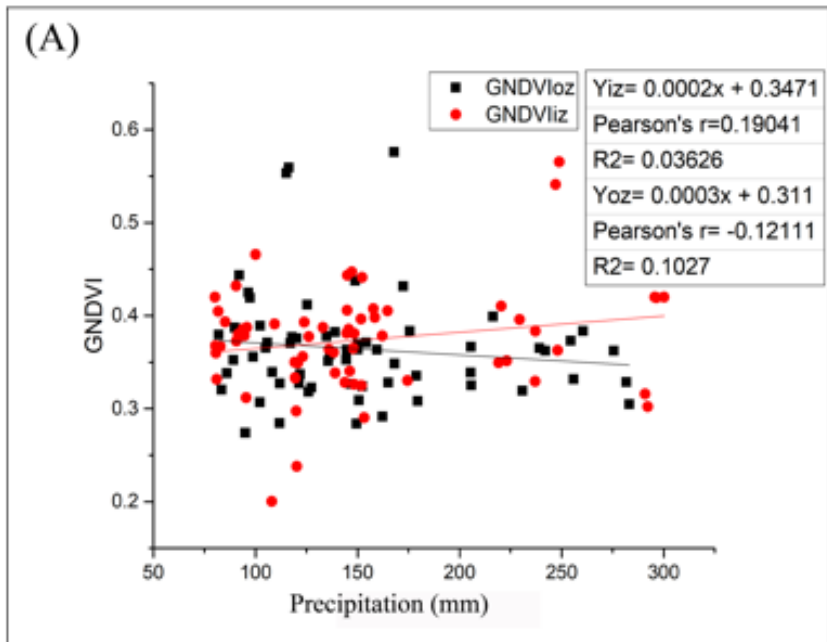

(B)

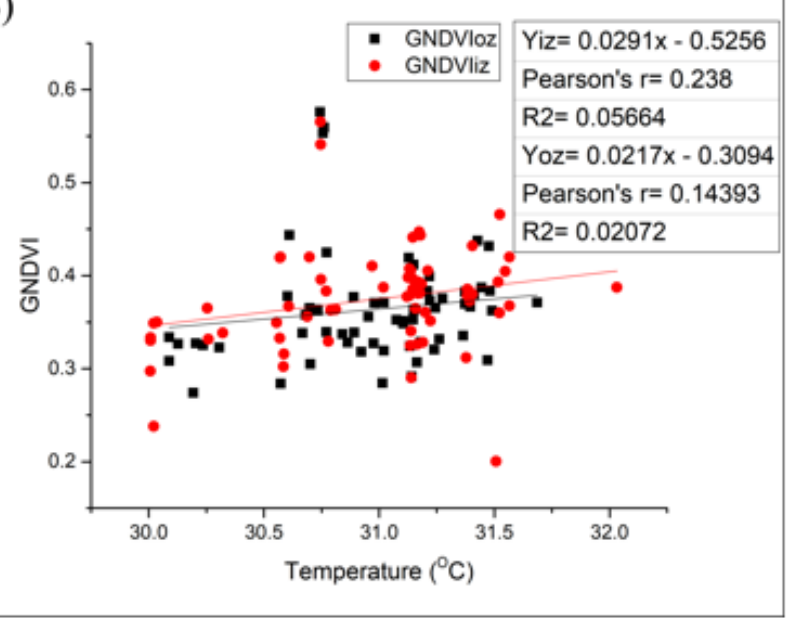

Figure 8

Correlation analysis between the mean annual (A) GP and GNDVI (B) GT and GNDVI. 

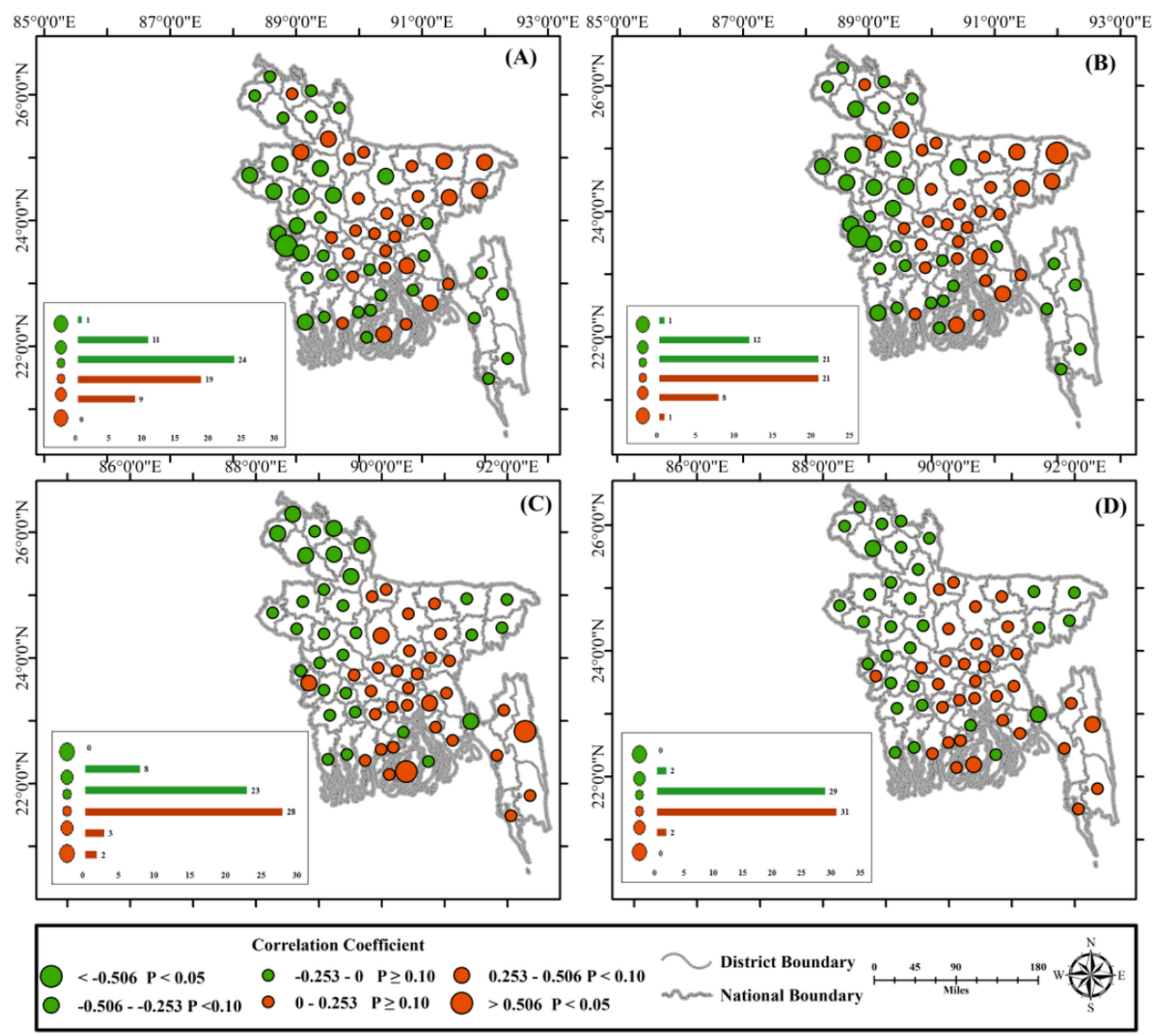

Figure 9

Correlation coefficient distributions for the variation between (A) GT and $\triangle \mathrm{PULIZ} \mathrm{(B)} \mathrm{GT} \mathrm{and} \triangle \mathrm{PULOZ}$ (C) GP and $\triangle \mathrm{PULIZ}$ (D) GP and $\triangle$ PULIZ during 1990-2018. 

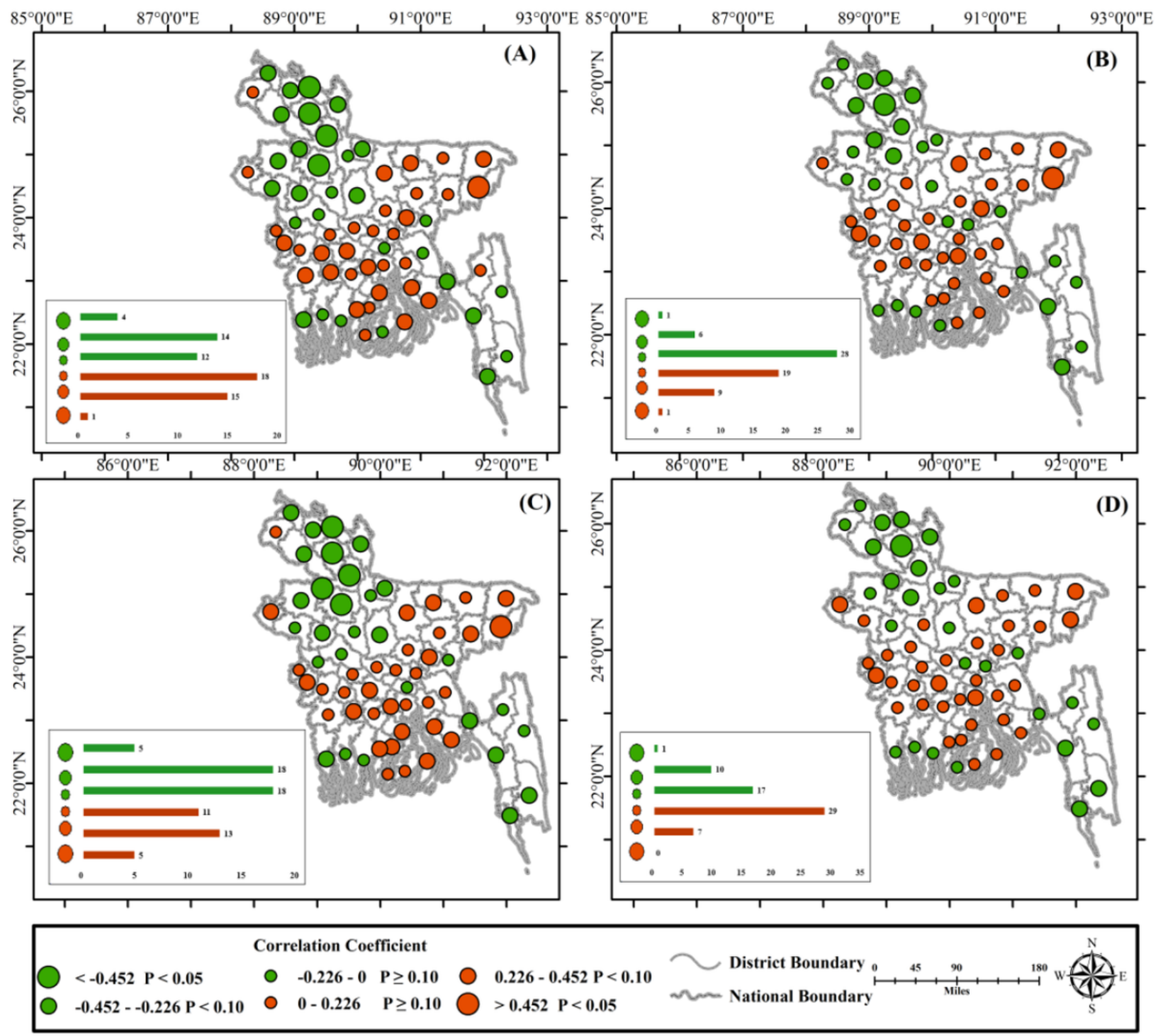

Figure 10

Correlation coefficient distributions for the variation between (A) GNDVIIZ and $\triangle$ PULIZ (B) GNDVIIZ and $\triangle P$ PULZ (C) GNDVIOZ and $\triangle$ PULIZ (D) GNDVIOZ and $\triangle$ PULOZ during 1990-2018. 


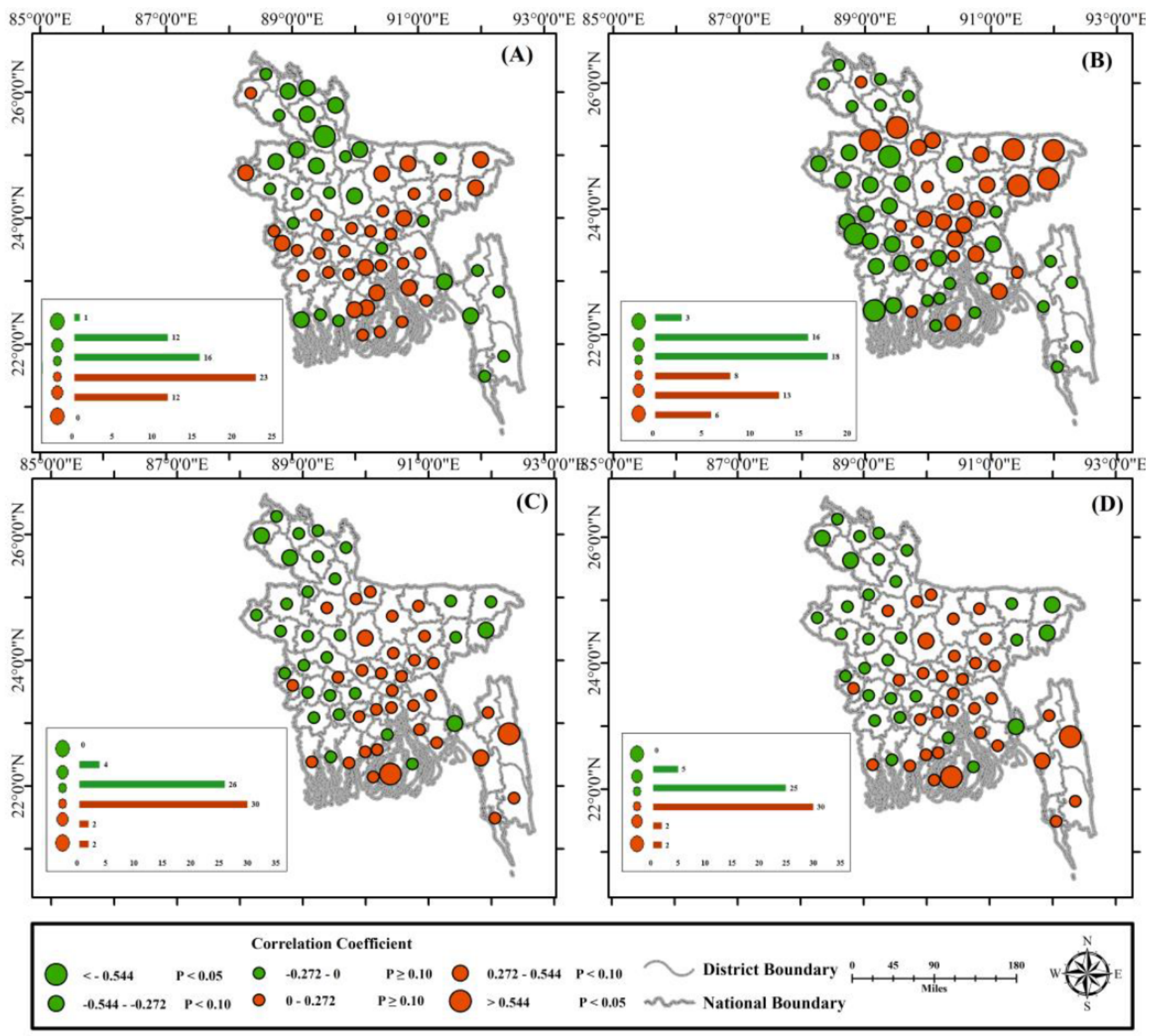

Figure 11

Correlation coefficient distributions for the variation between (A) GT and GNDVIIZ (B) GT and GNDVIOZ (C) GP and GNDVIIZ (D) GP and GNDVIIZ during 1990-2018. 

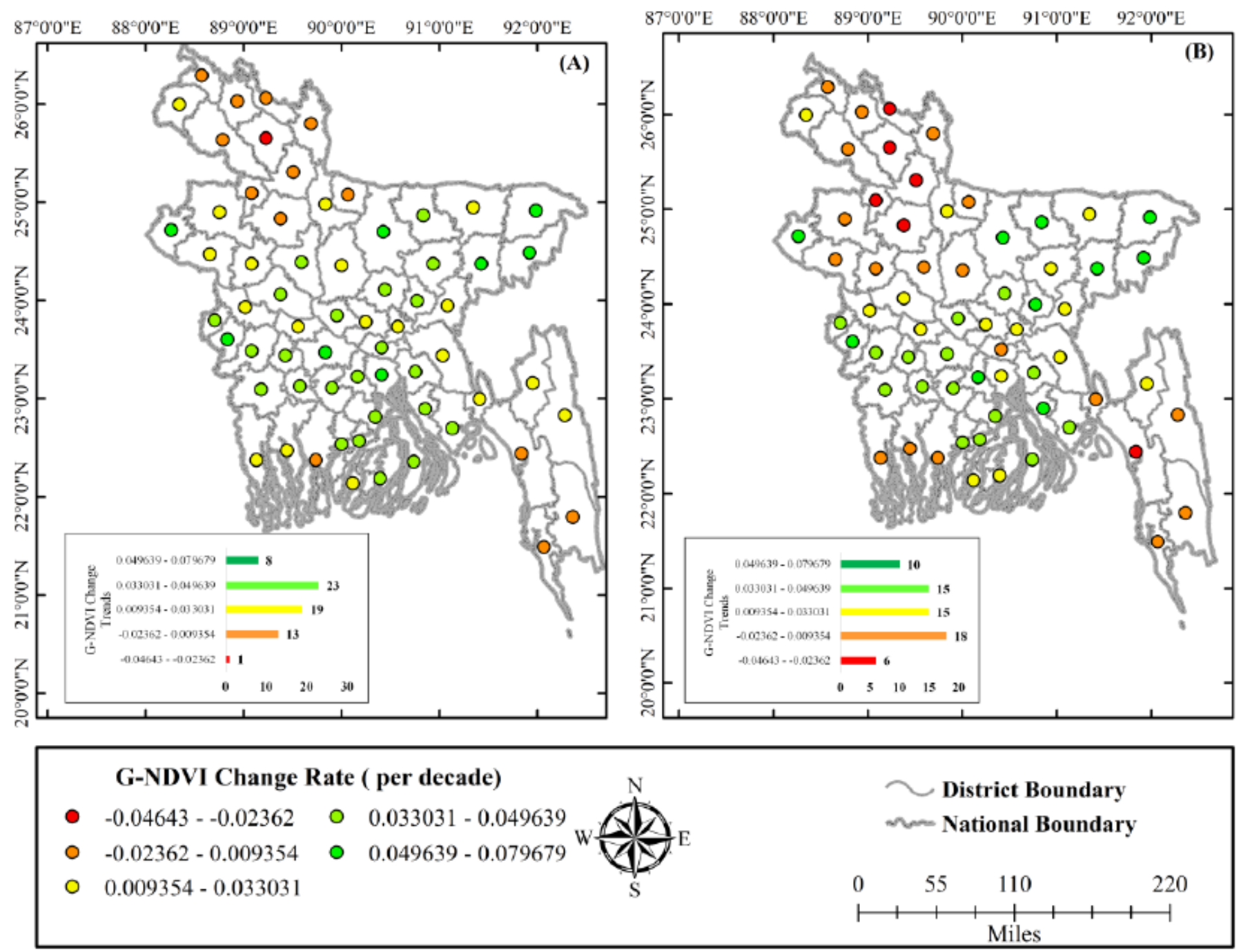

Figure 12

GNDVI change trends for (A) inner zone (B) outer zone during 1994-2018.

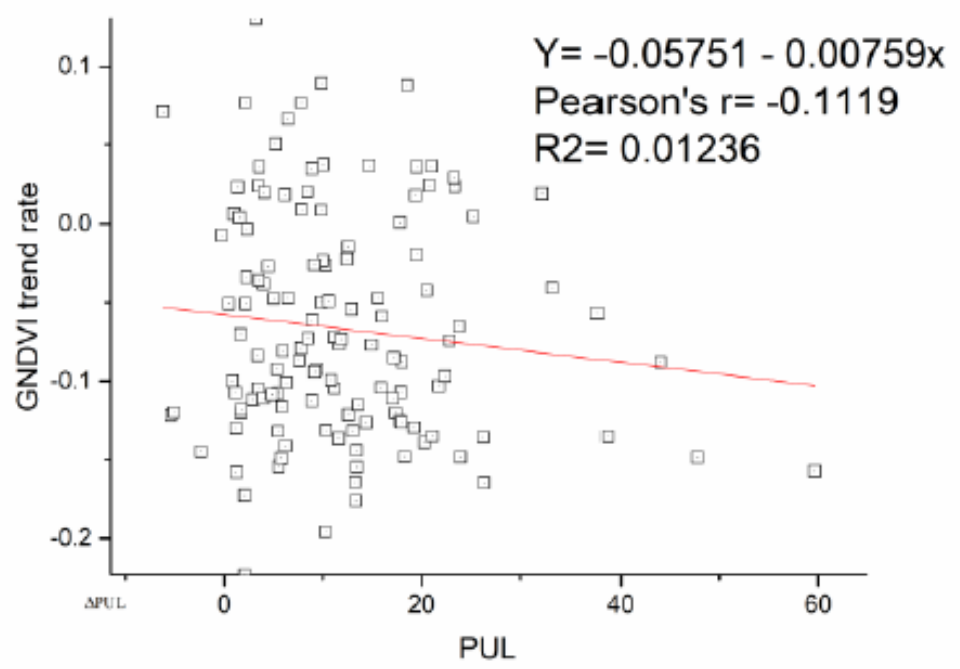

Figure 13

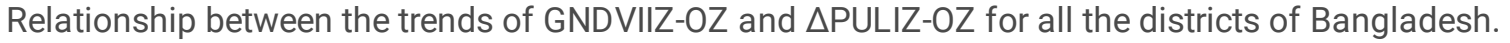

